\title{
ALUMINUM-STEEL CLAD MATERIAL PREPARED BY TWIN-ROLL CASTING
}

\author{
1'Barbora KŘIVSKÁ, ' Michaela ŠLAPÁKOVÁ, ${ }^{2}$ Olexander GRYDIN, ${ }^{1}$ Miroslav CIESLAR \\ ${ }^{1}$ Charles University, Faculty of Mathematics and Physics, Prague, Czech Republic, EU, \\ slapakova@karlov.mff.cuni.cz \\ 2University Paderborn, Faculty of Mechanical Engineering, Paderborn, Germany, EU
}

https://doi.org/10.37904/metal.2020.3595

\begin{abstract}
Both steel and aluminum alloys rank among the most important structural materials due to their suitable properties in various applications and low material cost. Bonding of such dissimilar materials and formation of a composite material can lead to an effective combination of steel high strength and aluminum low density and corrosion resistance. Fabrication of aluminum-steel clad material by twin-roll casting leads to preparation of composite material whose properties are governed by the microstructure of intermetallic layer between aluminum and steel. Such layer formed after annealing at $500^{\circ} \mathrm{C}$ for 16 hours by diffusion of iron atoms into aluminum.
\end{abstract}

Keywords: Aluminum-steel, clad material, twin-roll casting, microstructure

\section{INTRODUCTION}

Aluminum and iron alloys belong to a group of the most important engineering materials due to their exploitable properties in various applications and low material cost. Al alloys stand out among the materials in the field of engineering where low weight component or good corrosion resistance is required. Iron is the main constituent of steels, which are all-purpose materials for structural applications where high strength, good creep resistance and formability are needed.

Joining of two dissimilar materials for the purpose of formation of a composite material can bring unprecedent product characteristics beyond the ones of each conventional monomaterials [1-3]. The joints of steel and Al alloys seem very attractive due to the possible combination of low density of $\mathrm{Al}$ and high strength of steel and so the final material may be applied as a structural element in car bodies and chassis, aircraft constructions and ship building. Such conjunction can also provide high thermal conductivity and thermal capacity usable in heat exchangers [4] and smelting production of $\mathrm{Al}$ as well as in household applications [5].

Cladding is a procedure based on layering of different materials with continuous bonding layers $[6,7]$. The most common production method of the clad strips is cold or hot roll bonding [8], which makes more than $90 \%$ of all flat clad products. Nevertheless, these methods suffer from severe drawbacks - high energy and time consumption resulting in a high cost of the final product. The reason lies in the complicated preparation of substrates.

A possible alternative is twin-roll casting. One metal is fed on the roll's surfaces and so creates the outer shell of the strip. The other metal is fed internally and comes into contact with the thin outer shell and forms the core of the final bi-metal strip [9]. Method of horizontal twin-roll casting of the claded material uses combination of previously solidified sheet of the first metal and the melt of the second material [10]. The production was tested on different Al alloys. A higher strength was shown compared to hot roll-bonded composites. An experiment with a joining of two different metals (Al and Mg alloys) was first performed by Rao and Bae et al. [11,12] and intermetallic phases on the interface of the materials were investigated. 
The final properties of the clad materials are governed by the structure and thickness of the intermetallic layer which forms during subsequent heat treatment [13-15].

\section{EXPERIMENTAL}

Aluminum-steel clad sheets were produced by the means of twin-roll casting at the University of Paderborn. The laboratory twin-roll caster is equipped with two water-cooled rolls with a diameter of $370 \mathrm{~mm}$ and length of $200 \mathrm{~mm}$. A casting process was realized with a vertical operation plane. A solid austenitic steel (type 1.4301 [16]) strip with a thickness of $0.5 \mathrm{~mm}$ was fed into a gap between the rolls simultaneously with the melt of a technically pure aluminum EN AW-1070 [17].

Solidification of the aluminum melt is influenced by a presence of the steel strip on one side which behaves as an additional thermal barrier between the melt and the cooled roll so a shift of the metallurgical center of solidified aluminum occurs [18]. A layer of the solidified aluminum grows from the side of the uncovered roll and the steel substrate up to so-called "kissing point" that indicates the beginning of the deformation zone, where the metal sheet yields to a thickness reduction. Final thickness of the clad strip is $2.5 \mathrm{~mm}$.

In comparison to conventional roll-bonding, a flat grain structure of the aluminum substrate could be partially suppressed by the process of twin-roll cladding. This feature could influence the resulting mechanical properties. The formation of an interfacial layer of Al-Fe intermetallic phases could influence the bonding strength and other material properties of the composite $[5,19,20]$.

The microstructure of the cast material and material after annealing at $500{ }^{\circ} \mathrm{C}$ was studied by the means of light optical microscopy - Zeiss Axio Observer and scanning electron microscopy (SEM) - FEI Quanta F200 equipped by energy-dispersive spectroscopy (EDS).

\section{RESULTS}

Concerning the microstructure of the cast aluminum layer, colonies of the primary phases were arranged rather in chains orientated in the casting direction on both outer parts of the aluminum layer whereas in the central part the smaller round particles were randomly distributed. Occasionally, central segregations were present near the center of the strip (Figure 1) [21]. A slight difference of the phase distribution on the opposite edges of the aluminum layer (with and without the adjacent steel substrate) was noticed.

In the interfacial region, no continuous intermetallic layer was found. Nevertheless, larger density of the primary phases than on the other side of the aluminum layer was observed. This feature was probably consequence of the presence of the steel strip which impeded the heat flux during the casting.

Grain structure and phase distribution was further studied by scanning electron microscope (Figure 2). An equiaxed grain structure through the whole thickness of the steel strip was revealed in the channeling contrast. Moreover, it could be seen that many of the grains contain twins.

Dendritic colonies with eutectic features were found in the aluminum layer near the interface. Some regions containing only smaller particles of the primary phases close to the joint were also present. A variance of the phase arrangement through the Al layer was also observed. Primary phases formed linear chains and decorated the grain boundaries of the equiaxed aluminum grains. Towards the central part of the strip, primary phases comprised small dendritic colonies rather than the linear chains or they were present in the aluminum matrix as round particles.

Study of the aluminum-steel interface did not reveal any continuous layer of the intermetallic phases. Rarely, only the tiny separated isles of the intermetallic phases were found on the aluminum-steel border. 


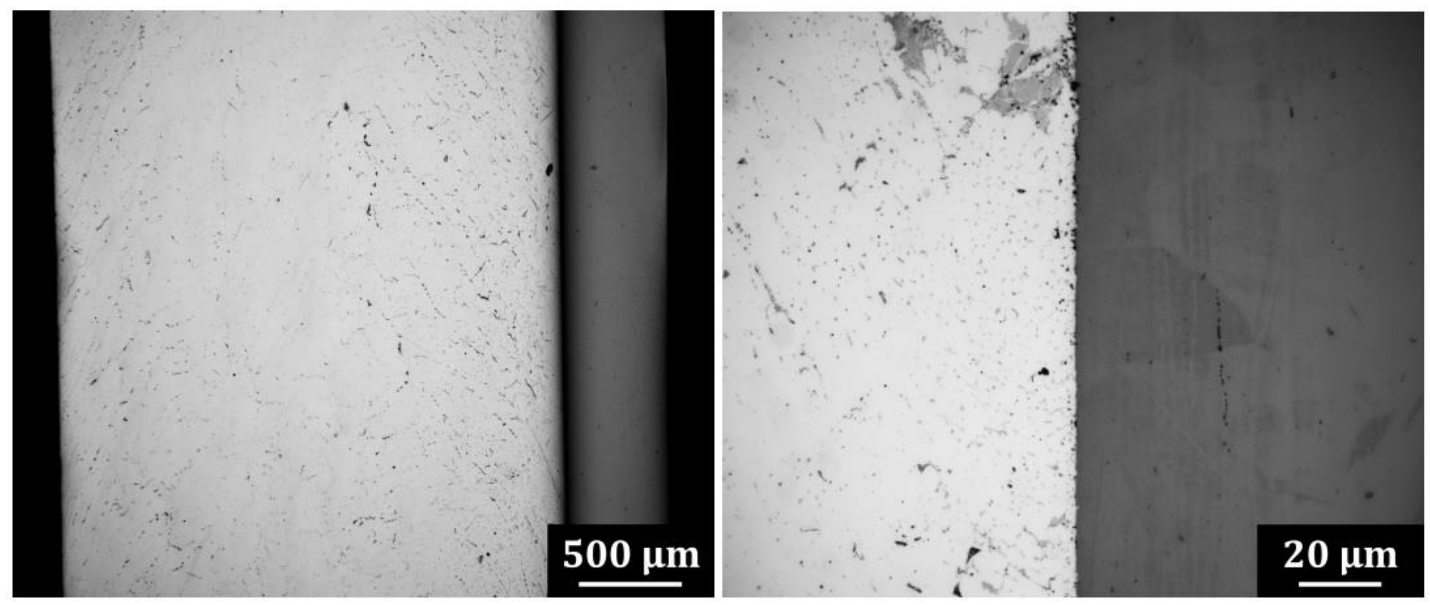

Figure 1 Micrograph through the whole clad strip thickness and detail of the interfacial region of the clad strip (steel is on right)

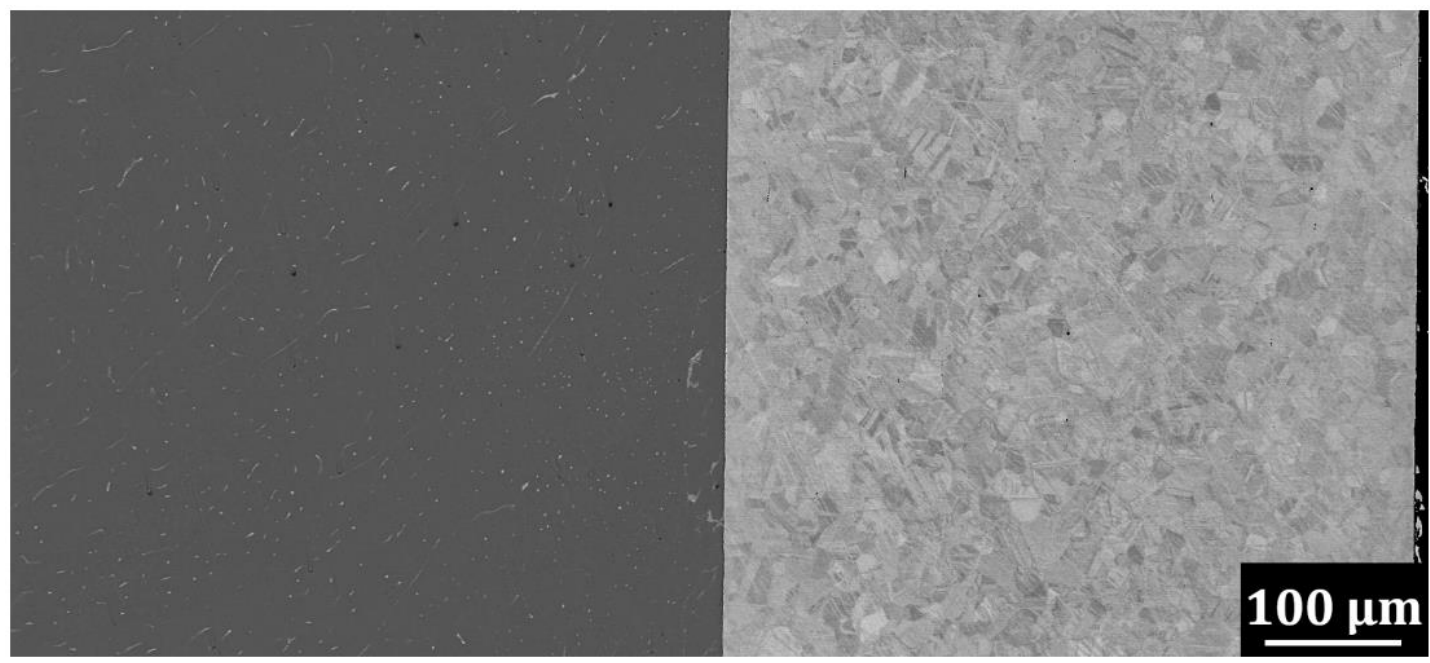

Figure 2 Microstructural overview from SEM. The whole thickness of the steel layer (right) was depicted.
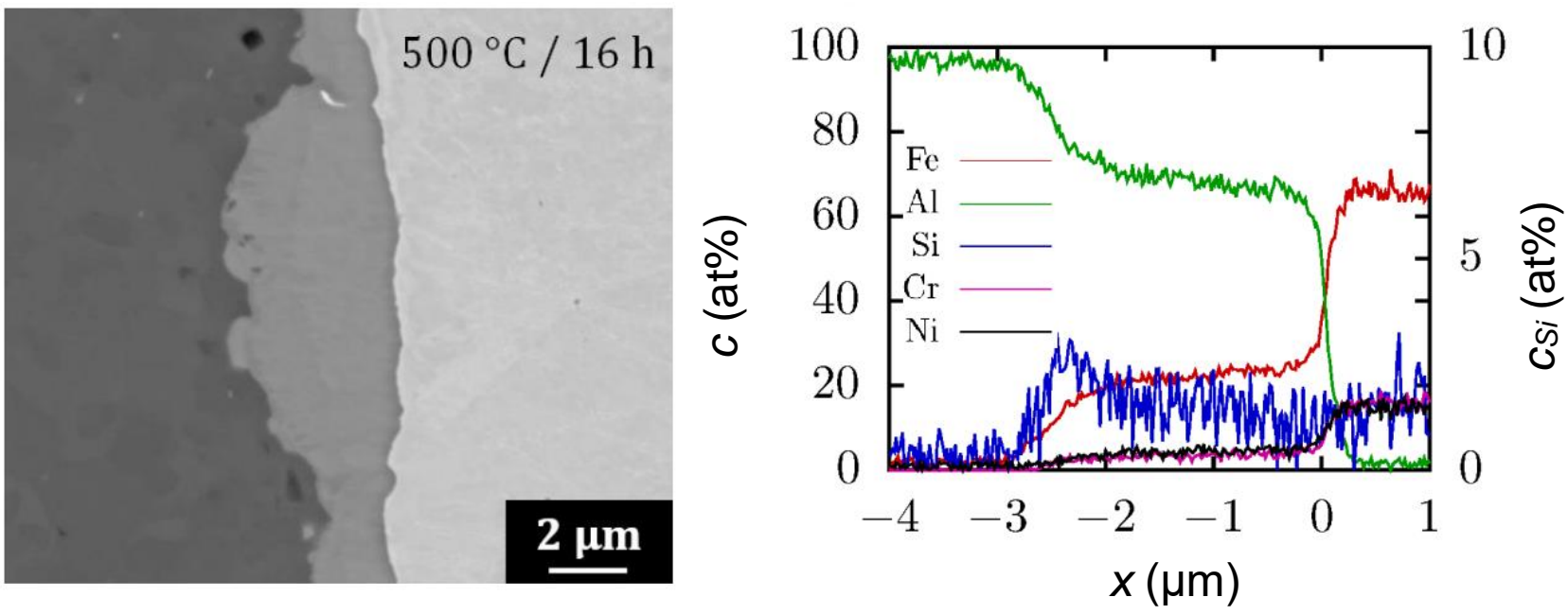

Figure 3 Detail of intermetallic layer formed at the interface between aluminum and steel layer and corresponding chemical analysis (right axis is for $\mathrm{Si}$ ) 
After annealing for 16 hours at $500{ }^{\circ} \mathrm{C}$ thick intermetallic layer was formed (Figure 3) between aluminum and steel. EDS line analysis of the concentration profile was carried out across the interface. Several analyses were performed due to uneven formation of intermetallic layer. Atomic concentrations as function of distance from a point of 50 at\% Al-concentration are displayed in Figure 3. In the intermetallic layer the concentration of $\mathrm{Al}$ decreased to $\sim 70$ at $\%$ and concentration of Fe increased to 20 at $\%$. Concentrations of $\mathrm{Cr}$ and $\mathrm{Ni}$ from the steel also increased, indicating that the intermetallic layer grew from steel towards aluminum. This phenomenon was also observed by other authors [14,22]. Slightly raised Si-concentration was measured in the interfacial phase near Al. As the Si content is low in comparison with remaining elements, Si concentration was scaled by right $y$-axes which was added for better resolution (Figure $\mathbf{3}$ ).

\section{CONCLUSION}

In this work, the Al-steel clad material prepared by twin-roll casting was studied. As-cast microstructure of the aluminum layer was inhomogeneous typical for twin-roll cast material containing colonies of Al-Fe-Si-base primary particles. Microstructure of the steel strip contained austenitic microstructure with a content of annealing twins. Almost no intermetallic layer was found on the Al-steel joint.

After annealing at $500{ }^{\circ} \mathrm{C}$ the interface layer of $\mathrm{Al}-\mathrm{Fe}$ was formed due to diffusion of Fe from the steel towards the aluminum.

\section{ACKNOWLEDGEMENTS}

\section{The financial support of Czech Scientific Foundation 20-00355Y and SVV-260582 are highly acknowledged.}

\section{REFERENCES}

[1] GRYDIN, O., GERSTEIN, G., NÜRNBERGER, F., SCHAPER, M., DANCHENKO, V. Twin-roll casting of aluminum-steel clad strips. Journal of Manufacturing Processes. 2013, vol. 15, no. 4, pp. 501-507.

[2] BABOIAN, R., GARDNER, H. ASM Handbook, Corrosion. Volume 13. ASM International, 1987.

[3] CHEN, L., YANG, Z., JHA, B., XIA, G., STEVENSON, J.W. Clad metals, roll bonding and their applications for SOFC interconnects. Journal of Power Sources. 2005, vol. 152, pp. 40-45.

[4] GRYDIN, O., SCHAPER, M., STOLBCHENKO, M. Comparison of twin-roll casting and high-temperature roll bonding for steel-clad aluminum strip production. Light Metals. 2015, pp. 1225-1230.

[5] SPRINGER, H., KOSTKA, A., PAYTON, E.J., RAABE, D., KAYSSER-PYZALLA, A., EGGELER, G. On the formation and growth of intermetallic phases during interdiffusion between low-carbon steel and aluminum alloys. Acta Materialia. 2011, vol. 59, no. 4, pp. 1586-1600.

[6] LIU, X., BAI, R., UY, B., BAN, H. Material properties and stress-strain curves for titanium-clad bimetallic steels. Journal of Constructional Steel Research. 2019, vol. 162, pp. 105756.

[7] LI, B.X., CHEN, Z.J., HE, W.J., WANG, P.J., LIN, J.S., WANG, Y., PENG, L., LI, J., LIU, Q. Effect of interlayer material and rolling temperature on microstructures and mechanical properties of titanium/steel clad plates. Materials Science and Engineering: A. vol. 749, pp. 241-248.

[8] KHALEDI, K., REZAEI, S., WULFINGHOFF, S., REESE, S. Modeling of joining by plastic deformation using a bonding interface finite element. International Journal of Solids and Structures. 2018, vol. 160, pp. 68-79.

[9] HUDSON, E.B. Direct casting of sheet like metal structures. 1936. US Patent No. 2128941.

[10] PAPICH, K.S. Method of continuously casting composite strip. 1997. US Patent No. 5669436.

[11] PRASADA RAO, A.K., KYUNGHWAN KIM, BAE, J., BAE, G.T., DONG SHIN, NACK KIM. Twin-roll cast Al-clad magnesium alloy. Materials Science Forum. 2009, vol. 618-619, pp. 467-471.

[12] BAE, J., PRASADA RAO, A.K., KYU HAN KIM, NACK KIM. Cladding of Mg alloy with Al by twin-roll casting. Scripta Materialia. 2011, vol. 64, no. 9, pp. 836-839. 
[13] PADMANABHAN, R., OLIVEIRA, M.C., MENEZES, L.F. 5 - lightweight metal alloy tailor welded blanks. In Brad L. Kinsey and Xin Wu, editors, Tailor Welded Blanks for Advanced Manufacturing, Woodhead Publishing Series in Welding and Other Joining Technologies, pp. 97-117. Woodhead Publishing, 2011.

[14] RUIDI LI, TIECHUI YUAN, XIAOJUN LIU, KECHAO ZHOU. Enhanced atomic diffusion of Fe-Al diffusion couple during spark plasma sintering. Scripta Materialia. 2016, vol. 110, pp. 105-108.

[15] JIAN AN, YONGBING LIU, YOU LU, DAREN SUN. Hot roll bonding of Al-Pb-bearing alloy strips and steel sheets using an aluminized interlayer. Materials Characterization. 2001, vol. 47, no. 3, pp. 291-297.

[16] Stainless Steel Type 304-304L [online]. Accessed: 2020-03-24. Available from: https://rolledmetalproducts.com/stainless-steel-type-304-304I/

[17] Material properties, EN AW-1070 [online]. Accessed: 2020-03-24. Available from: https://www.makeitfrom.com/material-properties/1070A-O-Aluminum

[18] STOLBCHENKO, M., GRYDIN, O., SAMSONENKO, A., KHVIST, V., SCHAPER, M. Numerical analysis of the twin-roll casting of thin aluminum-steel clad strips. Forschung im Ingenieurwesen. 2014, vol. 78, pp. 121-130.

[19] STOLBCHENKO, M., GRYDIN, O., SCHAPER, M. Manufacturing and characterization of twin-roll cast aluminum-steel clad strips. Advanced Engineering Materials. 2019, vol. 21, no. 4, pp. 1800454.

[20] WANG, Q., LENG, X.-S., YANG, T.-H., YAN, J.-C. Effects of Fe-Al intermetallic compounds on interfacial bonding of clad materials. Transactions of Nonferrous Metals Society of China. 2014, vol. 24, pp. 279-284.

[21] ŠLAPÁKOVÁ POKOVÁ, M., ZIMINA, M., ZAUNSCHIRM, S., KASTNER, J., BAJER, J., CIESLAR, M. 3D analysis of macrosegregation in twin-roll cast AA3003 alloy. Materials Characterization. 2016, vol. 118, pp. 44-49.

[22] MANESH, H. Assessment of surface bonding strength in Al clad steel strip using electrical resistivity and peeling tests. Materials Science and Technology. 2006, vol. 22, pp. 634-640. 